\title{
HETERARQUIZAÇÃO DO ESTADO E A EXPANSÃO DAS FRONTEIRAS DA PRIVATIZAÇÃO DA EDUCAÇÃO EM SÃO PAULO
}

\author{
Fernando Cássio ${ }^{1}$ \\ Marina Avelar ${ }^{2}$ \\ RODRIGO TrAVITZKI ${ }^{3}$
}

Thais Andrea Furigo Novaes ${ }^{4}$

\begin{abstract}
RESUMO: O artigo analisa a parceria público-privada entre a Secretaria da Educação do Estado de São Paulo (SEE-SP) e a Associação Parceiros da Educação (APE) em torno do Programa Educação - Compromisso de São Paulo, no período 2015-2018. A parceria serviu como modelo de estudo das relações público-privadas na educação, à luz dos conceitos de neoliberalização e heterarquização. Utilizando um algoritmo capaz de inferir redes políticas a partir de documentos físicos digitalizados, identificamos três dinâmicas de complexificação da privatização da educação em São Paulo: 1) a incorporação da APE na estrutura de governança da educação pública; 2) a porosidade entre políticas educacionais e a mobilidade da APE para além do escopo inicial da parceria; e 3) a atuação da APE na ampliação da rede de governança, atuando como boundary spanner e facilitando a entrada de outras organizações privadas.
\end{abstract}

Palavras-chave: Políticas educacionais. Privatização da educação. Governança. Parceria público-privada. São Paulo (estado).

\section{HETERARCHIZATION OF THE STATE AND THE EXPANDING BOUNDARIES OF EDUCATION PRIVATIZATION IN THE STATE OF SÃO PAULO}

\begin{abstract}
The article analyzes the public-private partnership between the Secretariat of Education of the Brazilian state of São Paulo (SEE-SP; in Portuguese, Secretaria da Educação do Estado de São Paulo) and the non-profit organization Partners of Education Association (APE; in Portuguese, Associação Parceiros da Educação) in the Program Education - São Paulo’s Commitment (Educação Compromisso de São Paulo) from 2015 to 2018. The partnership was used as a case
\end{abstract}

\footnotetext{
Este artigo resulta do projeto de pesquisa "Política Educacional na Rede Estadual Paulista (1995 a 2018)", financiado pela Fundação de Amparo à Pesquisa do Estado de São Paulo (n. 2018/09983-0) e coordenado por Márcia Aparecida Jacomini. Também deriva de diversos trabalhos de pesquisa-intervenção da Rede Escola Pública e Universidade (REPU), disponíveis em: www.repu.com.br.

1.Universidade Federal do ABC - Santo André (SP), Brasil. E-mail: fernando.cassio@ufabc.edu.br

2.Network for International Policies and Cooperation in Education and Training - Genebra, Suíça. E-mail: marinadeavelar@gmail.com 3.Universidade São Francisco - Campinas (SP), Brasil. E-mail: r.travitzki@gmail.com

4.Universidade Federal do ABC - Santo André (SP), Brasil. E-mail: thais.furigo.novaes@gmail.com
} 
study for public-private relationships in education, according to the concepts of neoliberalization and heterarchization. By applying an algorithm able to infer political networks from physical digitalized documents, three dynamics of complexification of the education privatization in São Paulo were identified: 1) the incorporation of APE in the structure of public education governance; 2 ) the porosity between educational policies and the APE's mobility beyond the initial scope of the partnership; and 3) the APE's role in expanding the network of governance, acting as a boundary spanner and facilitating the entry of other private organizations.

Keywords: Education policy. Privatization of education. Governance. Public-private partnership. São Paulo (Brazilian state).

\section{HETERARQUIZACIÓN DEL ESTADO Y LA AMPLIACIÓN DE LAS FRONTERAS DE LA PRIVATIZACIÓN DE LA EDUCACIÓN EN SÃO PAULO}

RESUMEN: El artículo analiza la alianza público-privada entre la Secretaría de Educación del Estado de São Paulo (SEE-SP), en Brasil, y la Associação Parceiros da Educação (APE) en torno al Programa Educación - Compromiso de São Paulo, en el período de 2015 a 2018. La alianza sirvió de modelo para el estudio de las relaciones público-privadas en la educación, a la luz de los conceptos de neoliberalización y heterarquización. Utilizando un algoritmo capaz de inferir redes políticas a partir de documentos físicos digitalizados, identificamos tres dinámicas de complejificación de la privatización de la educación en São Paulo: 1) la incorporación de la APE en la estructura de gobernanza de la educación pública; 2) la porosidad entre las políticas educativas y la movilidad de la APE más allá del alcance inicial de la alianza; y 3) el papel de la APE en la expansión de la red de gobernanza, actuando como boundary spanner y facilitando la entrada de otras organizaciones privadas.

Palabras-clave: Políticas educativas. Privatización de la educación. Gobernanza. Alianza público-privada. São Paulo (estado de Brasil).

\section{Introdução}

A

privatização dos serviços públicos, crescente tendência internacional desde os anos 1990, tem evidentes impactos na educação. Ela ocorre tanto em sentido estrito como em sentido amplo; ou seja, o avanço da participação de atores privados na educação pública se manifesta tanto na oferta do ensino quanto de forma mais sutil, nos espaços de formulação, gestão e avaliação das políticas educacionais.

A privatização em sentido estrito compreende a oferta direta de serviços educacionais por entidades privadas, seja via serviços de gestão educacional, de formação de professores e de produção de materiais de ensino, seja pela oferta de vagas em instituições privadas, especialmente na etapa da educação infantil (ADRIÃO; PERONI, 2005; ADRIÃO et al., 2012). Já a privatização em sentido amplo, fenômeno bem mais difuso, é vista a partir daquilo que se tem denominado "redes políticas" (BALL, 2012, 2016; SHIROMA; EVANGELISTA, 2014; SHIROMA, 2020), que redefinem as fronteiras entre o público e o privado. Essas redes vêm ganhando importância no desenvolvimento das políticas educacionais e dos sentidos e discursos mobilizados pela gestão da educação pública. Daí a necessidade de produzir análises cada vez mais descentradas 
e atentas à permeabilidade estatal, menos focalizadas no governo do que na governança (RHODES, 1996; JESSOP, 2002, 2016; TRIPODI; SOUSA, 2018).

O Programa Educação - Compromisso de São Paulo (PECSP) é um exemplo de política pública que engajou organizações privadas de forma ativa na gestão pública e na formulação das políticas educacionais da maior rede pública de ensino do Brasil. Iniciado em 2011, o PECSP foi definido pelo governo do estado de São Paulo como "um passo decisivo para a mobilização da sociedade paulista pela melhoria do ensino público"; "um marco no engajamento de todos os paulistas para dar às crianças e aos jovens do estado uma educação à altura dos padrões internacionais"

Assumido inicialmente como um "programa de estado", o PECSP teve um ponto de inflexão, em 2014, quando a Secretaria da Educação do Estado de São Paulo (SEE-SP) formalizou um convênio com a Associação Parceiros da Educação (APE) para viabilizar "os mecanismos organizacionais para operacionalizar o PECSP” (SÃO PAULO, 2018, f. 405-406). Com isso, a política de estado passou a se confundir com a própria parceria público-privada.

Não obstante as relações entre a SEE-SP e a APE tenham se estabelecido ainda na década de 2000 e o PECSP tenha, de maneira informal, elevado tal organização à condição de agente executor das políticas educacionais do estado de São Paulo já em 2011, a contratualização da parceria público-privada modificou substantivamente as formas de execução do PECSP a partir de 2015. A APE passou a operar formal e diretamente uma série de projetos e programas da SEE-SP, intermediou relações e trouxe para o âmbito do PECSP diversas outras organizações. Essa atuação não apenas ampliou a constelação de atores privados junto à SEE-SP, mas também criou e complexificou as redes de governança envolvidas na gestão e na formulação das políticas educacionais no estado de São Paulo. Fez, a um só tempo, avançar a neoliberalização (BRENNER et al., 2010) e a heterarquização do estado (JESSOP, 2016). À luz desses conceitos, a parceria público-privada entre a SEE-SP e a APE em torno do PECSP serviu, neste trabalho, como um modelo para investigar os processos de complexificação das relações público-privadas na educação.

O recorte temporal adotado - o quadriênio 2015-2018 - justifica-se tanto pela disponibilidade de fontes primárias quanto pela especificidade na forma de execução do PECSP em relação ao quadriênio anterior, o que será detalhado ao longo do artigo com o apoio das fontes. Para além de suas contribuições empíricas e teóricas, o artigo também avança em termos de método. Desenvolvemos um algoritmo capaz de identificar co-ocorrências de palavras em documentos físicos de grande extensão e, a partir disso, inferir redes de relações entre atores, organizações e políticas públicas. Auxiliados pela ferramenta, partimos do processo administrativo de acompanhamento do PECSP - que inclui um grande volume de minutas, termos e aditamentos de contrato, pareceres técnicos, planos de trabalho, prestações de contas, memorandos, despachos e modelagens de programas - para investigar o adensamento das redes de relacionamentos públicoprivados na educação paulista, explorar algumas nuances dessas relações e avançar na compreensão de que a privatização da educação é um fenômeno simultaneamente produzido com/por agentes governamentais e não governamentais, de maneira sempre mais difusa e horizontalizada.

\section{A Complexificação das Relações Público-privadas na Educação}

Para muito além da transferência de patrimônio e de responsabilidades do setor público para o privado, a privatização da educação se relaciona a um contínuo processo de reorganização e reformulação do próprio Estado. As novas relações e fronteiras entre o público e o privado decorrem de concepções renovadas sobre os papéis sociais do mercado, da sociedade civil e do Estado (PERONI, 2013; ADRIÃO, 2018), o qual, 
por sua vez, vai se livrando de seu papel provedor dos serviços sociais para se tornar criador e árbitro do mercado concorrencial e gestor de redes de relações (DARDOT; LAVAL, 2016, p. 69; JESSOP, 2002, 2016).

Nesse tipo de arranjo, os atores privados são tidos como "necessários", em vista da alegada insuficiência ou incompetência do Estado para lidar com problemas públicos considerados "intratáveis" (BALL, 2016). Herman J. C. Voorwald, secretário da educação de São Paulo entre janeiro de 2011 e dezembro de 2015, período em que o PECSP foi iniciado, é um feérico defensor dessas ideias, articuladas na publicação retrospectiva de seus cinco anos à frente da SEE-SP (VOORWALD, 2017). O livro A educação básica pública tem solução? é uma espécie de exercício contrafactual, em que o ex-secretário expõe as propostas que teria levado adiante caso sua saída da SEE-SP não fosse precipitada pelas contingências políticas ${ }^{2}$. Dois anos após a sua exoneração do cargo, o ex-secretário justificou o desenho do PECSP como uma resposta necessária a demandas de eficiência, planejamento, controle e avaliação, com definição de metas e medição de resultados na educação (VOORWALD, 2017, p. 48). É desta maneira que Voorwald resume as suas concepções sobre o papel do Estado e as relações desse com a sociedade civil - concepções que, segundo ele, sustentaram o PECSP:

Em uma Rede de Educação Básica Pública extensa como a do estado de São Paulo, as demandas são cada vez mais fragmentadas, oriundas de públicos variados e necessidades particulares, o que coloca em dúvida a definição de políticas públicas universalizantes. A necessidade de respostas rápidas a questões específicas e a atuação crescente de atores sociais como associações de bairro, ONGs e sociedade civil organizada retiram do Estado parte do papel de formulação e implantação das políticas. Assim, o foco passa a ser a organização e a gestão dessas ações (VOORWALD, 2017, p. 49-50).

Defensores, proponentes e iniciativas desse modelo de gestão neoliberal em rede - como Voorwald, a APE e o PECSP - enformam um vasto processo de reforma do estado, que alguns autores denominaram "neoliberalização" (LARNER, 2003; BRENNER et al., 2010) e que "representa uma tendência historicamente específica, desigualmente desenvolvida, híbrida e padronizada de reestruturação regulatória pela disciplina do mercado" (BRENNER et al., 2010, p. 330). A neoliberalização produz novas formas de governança para impor ou para consolidar a mercantilização e a comoditização da vida social.

A crítica ao neoliberalismo, como sublinham Dardot e Laval (2016), jamais pode equivaler à crítica ao laissez-faire, à ideia de "Estado mínimo" ou ao próprio regime de acumulação capitalista. Por isso mesmo, o modo neoliberal de ação pública não pode ser concebido como um processo de desengajamento do Estado, meramente destrutivo, mas como um regime de evidências que se impõe aos governantes como "único quadro de inteligibilidade da conduta humana" (DARDOT; LAVAL, 2016, p. 193). Essa neoliberalização "construtiva" compreende interações, tensões, conflitos, disputas e avanços dependentes do contexto e do local, que impõem aos pesquisadores um considerável desafio analítico (BRENNER et al., 2010). O esforço de analisar esses processos complexos, por seu turno, ajuda a criar e a fortalecer espaços de resistência à neoliberalização, a "superar o medo e a desesperança gerados pelas narrativas monolíticas do projeto 'neoliberal"' (LARNER, 2003, p. 512).

A crescente participação de atores não estatais na gestão pública é parte da neoliberalização. Nesse processo, a estrutura hierarquizada do Estado vai sendo modificada para dar lugar a uma organização em que o governo divide a centralidade com outros atores, em uma estrutura "heterárquica". Compreende-se a heterarquia como "uma forma organizacional entre a hierarquia e a rede, baseada em diversos vínculos horizontais e verticais que permitem que diferentes elementos do processo político cooperem (ou entrem 
em competição)" (BALL; JUNEMANN, 2012, p. 138). Contudo, como tal mudança é também processual, a ela poderíamos chamar "heterarquização" (JESSOP, 2016; AVELAR; BALL, 2019): um processo de deshierarquização do Estado, pelo qual este busca reiterar (ou restaurar) seu controle social por meio de novas formas de governo, viabilizadas, sobretudo, por parcerias público-privadas.

Em meio às estruturas heterárquicas da governança em rede, pessoas e organizações transitam continuamente entre o público e o privado. Alguns desses atores desenvolvem ferramentas para fomentar ativamente esses fluxos, sendo capazes de atravessar e expandir fronteiras, de conectar e de promover colaborações dentro e através de redes, compartilhando objetivos e recursos materiais e imateriais (BALL, 2016, p. 33). São os denominados boundary spanners (WILLIAMS, 2002).

Esses atores mobilizam a sua posição específica de acesso às esferas pública e privada e empregam seus recursos em práticas corporativas de networking. Movimentam pessoas e ideias, proporcionando viagens e organizando eventos e reuniões, além de utilizarem tecnologias da informação e da comunicação. Nesses circuitos, reúnem "parceiros improváveis", que "veem as coisas de formas diferentes" (WILLIAMS, 2002, p. 109) e chegam a produzir mudanças institucionais. Ao multiplicarem as conexões entre os setores público e privado, os boundary spanners desafiam as estruturas do governo hierárquico e implementam novas formas de governança, catalisando processos de neoliberalização e de heterarquização. Eles conectam grupos que não estariam conectados de outra forma em uma determinada rede social. A análise empírica permite localizar os boundary spanners nas redes, identificar fluxos de comunicação e pontos específicos de conexão (LONG et al., 2013). O termo "boundary spanner" pode assumir diferentes significados, a depender do campo de pesquisa que o emprega. Na ciência política e na sociologia, e, por conseguinte, nas pesquisas em política educacional, boundary spanner se tornou sinônimo do agente que conecta os setores público e privado.

\section{Método e Fontes de Pesquisa}

Além de leis, decretos, normativas da SEE-SP e materiais de imprensa e partidários - fontes documentais usuais na análise de arranjos público-privados -, a existência de um convênio formal relacionado ao PECSP nos legou uma fonte primária adicional para a análise das políticas educacionais do governo paulista no período investigado: o processo administrativo de acompanhamento do convênio. Nele, são juntados contratos, aditamentos e suas minutas, planos de trabalho, pareceres técnicos, jurídicos e de setores de regulação, despachos e memorandos internos, certidões negativas e informações profissionais dos parceiros privados, relatórios de trabalho detalhados e demais documentos relacionados ao objeto do contrato.

A Lei Estadual n. 6.544/1989, que dispõe sobre o estatuto jurídico das licitações e dos contratos no âmbito da administração centralizada e autárquica no estado de São Paulo, obriga o governo estadual a autuar processos administrativos para o acompanhamento de seus contratos (art. 35). Isso é reforçado por um conjunto de leis e decretos estaduais e federais, promulgados a partir de 2004 para disciplinar a contratação de parcerias público-privadas e regulamentar seu acompanhamento ${ }^{3}$. Em um relato de pesquisa de 2011, Di Pierro e Ximenes comentam sobre a utilização de processos administrativos e judiciais na análise de políticas educacionais, tanto para fins de pesquisa quanto com vistas ao aprofundamento do controle social das ações do Estado. No caso do PECSP e de processos administrativos relacionados a políticas educacionais recentes do governo do estado de São Paulo, eles também têm sido utilizados nos trabalhos da Rede Escola Pública e Universidade (REPU), com este duplo fim: pesquisa acadêmica e disseminação de conhecimento para o fortalecimento das lutas educacionais (GOULART et al., 2019). Aqui, a análise do processo administrativo permitiu investigar como entidades públicas e privadas se relacionam na prática, revelando as nuances da privatização da 
educação em sua dimensão processual, produzida simultaneamente com/por agentes governamentais e não governamentais e com/por pessoas jurídicas e físicas.

Nossa fonte documental principal foi o processo administrativo SEE n. 2.737/2014 ${ }^{4}$, referente ao convênio entre a SEE-SP e a APE para o desenvolvimento de atividades inerentes ao PECSP. Até agosto de 2018, os nove volumes do processo físico acumulavam mais de 2.000 folhas. Isso cria óbvias dificuldades para a realização de uma análise de redes sociais, que, nesse caso, precisaria ser antecedida de uma análise de conteúdo clássica do processo administrativo - fonte documental extensa e que inclui documentos de diferentes naturezas.

Para lidar com essa dificuldade, desenvolvemos uma ferramenta automatizada para a análise exploratória do processo administrativo, que nos permitiu identificar as conexões entre pessoas, instituições e projetos/programas e representá-las na forma de grafos (redes). O método não nos dispensa do trabalho de leitura das fontes, mas reduz substancialmente o tempo das análises, ampliando a nossa capacidade de trabalhar com corpora documentais extensos e permitindo a construção de quadros gerais minimamente objetivos de fenômenos complexos. O uso da ferramenta não encerra, mas contribui para a interpretação do fenômeno investigado e para a identificação de aspectos particulares que mereçam ser analisados por outros métodos.

O documento em papel foi fotografado na íntegra e digitalizado em formato PDF com Reconhecimento Ótico de Caracteres (OCR; do inglês, optical character recognition). Após essa etapa, os textos foram importados para o programa estatístico R, tendo sido removidos os caracteres de pontuação e a acentuação de todas as palavras. A identificação dos diversos documentos juntados aos volumes do processo - contratos, atas, pareceres, memorandos etc. - foi feita manualmente. Dados complementares sobre os atores privados (pessoas ou organizações) citados no processo foram coletados on-line.

A partir de leituras prévias e independentes do processo na íntegra, foi elaborada uma lista com 275 nomes-alvo a serem identificados nos nove volumes. A seleção dos nomes se deu tanto em razão de sua alta frequência nos documentos quanto por critérios objetivos: nomes de servidores da SEE-SP e de seus órgãos internos, de diretores e assessores de organizações privadas e de membros do Conselho Estadual de Educação de São Paulo (CEE-SP) citados no processo. Alguns nomes da lista foram incluídos tanto pelo nome completo quanto por sigla ou acrônimo, a fim de evitar ambiguidades (p. ex., que "SEE-SP" e "Secretaria da Educação" fossem identificados pelo algoritmo como elementos diferentes). Foi realizada ainda uma categorização prévia dos nomes incluídos na lista: 1) agentes privados; 2) agentes públicos; 3) servidores da SEE-SP; 4) membros do CEE-SP; 5) instituições privadas; 6) instituições/órgãos públicos; e 7) programas e projetos. O algoritmo ${ }^{5}$ verifica a co-ocorrência dos nomes da lista nos múltiplos documentos juntados ao processo, gerando grafos a partir dessas informações.

O procedimento é simples: se dois nomes da lista são encontrados em um mesmo documento (uma co-ocorrência), cria-se uma conexão e infere-se uma relação entre eles ${ }^{6}$. Por exemplo, se duas pessoas participam de uma mesma reunião ou firmam um determinado contrato, assumimos que exista uma relação entre elas. A natureza da relação é investigada depois, via análise qualitativa do documento ou cotejamento com dados complementares. Se os mesmos dois nomes da lista co-ocorrem em um segundo documento, a conexão entre eles no grafo é reforçada ${ }^{7}$. Os dados são incorporados em uma tabela denominada matriz de adjacência, representação matemática do grafo.

A representação gráfica das redes consiste em um conjunto de nós (ou vértices) conectados por linhas (ou arestas). Cada nó representa um ator, organização ou programa/projeto identificado nas fontes documentais. Cada linha representa uma relação (co-ocorrência) entre dois nós. Nos grafos, o reforço da conexão entre dois nós se traduz por uma maior espessura da aresta que os conecta (Figs. 2 e 3). 
Os grafos que obtivemos são monopartidos ${ }^{8}$ e não dirigidos ${ }^{9}$, tendo sido analisados inicialmente em suas propriedades básicas: modularidade (a presença de subgrupos, ou módulos) e aninhamento (o quão estruturada é a rede ao redor de um núcleo). Tendo sido gerados grafos de baixa modularidade - pois, como veremos, a rede política do PECSP não apresenta comunidades bem-definidas e separadas entre si -, calculamos algumas métricas relacionadas à centralidade topológica dos nós: o número de conexões de cada nó (sem levar em conta o peso de cada conexão) e o hub score, que leva em conta não apenas o peso, mas todas as conexões (diretas e indiretas) entre os nós. Assim identificamos os atores mais centrais - e, portanto, mais influentes - da rede política.

Como forma de validação do método, os relacionamentos entre organizações e pessoas no processo administrativo (parcerias institucionais, vínculos empregatícios etc.) também foram identificados manualmente e os resultados foram transformados em grafos com o Gephi, software livre largamente utilizado na análise de redes sociais. A despeito de algumas diferenças de forma entre os grafos obtidos (ver Fig. 1, em comparação às Figs. 2 e 3), suas características mais importantes - em especial a centralidade de certos atores, a posição relativa entre os nós e as conexões mais relevantes na rede - foram preservadas nas duas abordagens.

\section{O Programa Educação - Compromisso de São Paulo}

\section{Parcerias Informais e “Política de Estado” (2011-2014)}

No dia 15 de outubro de 2011 - Dia do Professor -, o Governador Geraldo Alckmin anunciou a criação do PECSP, cujos objetivos principais seriam "fazer a rede estadual de ensino alcançar níveis de excelência e valorizar a carreira de professor" ${ }^{10}$. O programa foi oficializado em 02 de dezembro de 2011, por meio do Decreto Estadual n. 57.571/2011, que explicitou a estrutura do PECSP em torno de cinco pilares: 1) valorização do capital humano; 2) gestão pedagógica com foco no aluno; 3 ) educação integral; 4) gestão organizacional e financeira; 5) mobilização e engajamento da rede e da sociedade em torno do processo de ensino e de aprendizagem.

De acordo com a SEE-SP, a elaboração do PECSP contou não apenas com o apoio das áreas técnicas da secretaria, mas foi alimentada por contribuições coligidas em um amplo processo de consulta à rede de ensino. A ênfase no "compromisso" entre Estado e sociedade foi também ressaltada, pelo

\footnotetext{
[...] apoio e envolvimento de diversas organizações e instituições, como Instituto Natura, Fundação Victor Civita, Fundação Lemann, Instituto Unibanco, Comunidade Educativa Cedac, Instituto Hedging-Griffo, Fundação Itaú Social, Tellus, [Associação] Parceiros da Educação, Fundação Educar DPaschoal, Fundação Bradesco, Centro de Estudos e Pesquisas em Educação, Cultura e Ação Comunitária (Cenpec), Instituto Península, Fundação Arymax e da consultoria internacional McKinsey \& Company ${ }^{11}$.
}

Apesar de a SEE-SP ter se esforçado para lastrear o PECSP sobre um amplo movimento de diálogo da secretaria com os atores escolares e mencionado um genérico "apoio e envolvimento de diversas organizações e instituições", pelo menos dois aportes provenientes de organizações do setor privado podem ser identificados no desenho inicial do PECSP.

O primeiro é o manifesto A transformação da qualidade da educação básica pública no brasil, divulgado em dezembro de $2010^{12}$ e assinado por Casa do Saber, Fundação Aprendiz, Fundação Bradesco, 
Fundação Educar, Instituto Ecofuturo, Instituto Natura, Instituto Unibanco e APE. Embora tal documento se afirme como uma proposta para a transformação da educação em nível nacional ${ }^{13}$, ele é apresentado no website da APE com a seguinte legenda:

Em 2011, esse envolvimento da [Associação] Parceiros [da Educação] com a política pública nos levou, em conjunto com outras 15 organizações da sociedade civil, a apoiar a Secretaria de Educação do Estado de São Paulo no desenvolvimento e implementação de um Plano de Estado para promovermos um salto de qualidade na educação pública do estado: o Programa Educação - Compromisso de São Paulo. Acesse aqui o documento ${ }^{14}$.

O "documento" em questão (o manifesto de 2010) é reivindicado pela APE como gérmen do PECSP. O Governador Geraldo Alckmin, na cerimônia de assinatura do Decreto n. 57.571/2011, confirmou o protagonismo da organização privada no processo de elaboração e implantação do PECSP:

Os Parceiros da Educação [a APE] estão nos ajudando a contratar as melhores consultorias no Brasil, de renome internacional, para o planejamento e execução dos projetos para colocarmos o sistema educacional de São Paulo entre os 25 melhores do mundo (02 dez. 2011) $)^{15}$.

O segundo aporte do setor privado identificável no PECSP provém da consultoria internacional McKinsey \& Company. Segundo um especialista em políticas públicas da Secretaria de Gestão Pública do Estado de São Paulo'o,

[...] em 2011, a partir de uma série de encontros do Secretário da Educação com a rede de ensino do estado de São Paulo e com o apoio da consultoria McKinsey \& Company, foi elaborado pela SEE-SP um plano que viria a embasar o programa "Educação - Compromisso de São Paulo" (DANTÔNIO, 2014).

João Cardoso Palma Filho, secretário-adjunto de Voorwald durante os primeiros anos do PECSP, declarou em entrevista de dezembro de 2011 que a "radiografia" da SEE-SP, realizada pela McKinsey \& Company em 2011, não acarretou custos para o governo paulista:

Os empresários pagaram. E foi uma coisa que começou no Palácio do Governo. Eles procuraram o Governador, o Governador falou com o secretário. Os empresários tão aí, um grupo de empresários: Jair Ribeiro; também Abílio Diniz, do Pão de Açúcar, esse pessoal aí. O pessoal da Natura, a Uniban (sic), o Itaú. Eles estão oferecendo. Você vai negar? Não vai querer? Primeiro pergunta: “Vai custar?” Não, não vai. É um diagnóstico pra nós. Ótimo, tá bom. Bom, recebemos. Agora, tá servindo pra gente? Não. Agora, os empresários que vão dirigir a secretaria? Vão nada. Não vão. Pelo menos enquanto eu estiver aqui (DANTAS, 2013, p. 91-92).

O PECSP foi a grande política educacional do estado de São Paulo nos dois últimos mandatos de Geraldo Alckmin (2011-2018), ao ponto de a ampliação de suas metas ter sido incluída no programa eleitoral da coligação "Aqui é São Paulo", que reelegeu Alckmin em 2014 ${ }^{17}$. Todavia, as formas de execução do PECSP nos quadriênios 2011-2014 e 2015-2018 foram visivelmente diferentes. Apesar da existência de 
uma parceria informal com a APE para a execução de determinadas atividades relacionadas ao PECSP no primeiro período, o programa era tido pela SEE-SP como um organizador de todas as ações de governo relacionadas à educação.

Isso fica claro na publicação que Voorwald e Palma Filho produziram para registrar os primeiros anos de execução do PECSP. Além de descrever o longo processo de consulta à rede de ensino, que, segundo eles, ajudou a gestar o PECSP, a publicação traz um anexo que lista todas as iniciativas, normativas, leis e decretos relativos à educação produzidos entre março de 2010 e julho de 2013 como ações - numeradas e sequenciais - relativas aos cinco pilares do PECSP (VOORWALD; PALMA FILHO, 2013, p. 107-151). Esse esforço de sistematização conferia centralidade e caráter unificador ao PECSP. Nessa direção, foi assim que Herman Voorwald definiu o PECSP em seu discurso comemorativo ao Dia do Professor de 2011:

Todas as grandes ações do Governo do Estado desencadeadas neste ano para a melhoria da qualidade do ensino não foram iniciativas isoladas. Cada uma delas integra um empreendimento muito mais amplo, que prevê novas medidas, com objetivos e metas de curto, médio e longo prazo, para se tornar muito mais que um programa de governo, um programa de Estado (15 out. 2011) ${ }^{18}$.

Isso mudou a partir de 2014, quando a assinatura de um contrato entre a SEE-SP e a APE para o apoio à gestão do PECSP tornou o "programa de Estado" praticamente indistinguível da parceria públicoprivada e consolidou a posição da APE como um ator central na implementação do PECSP - tão central quanto o próprio governo de São Paulo. Após 2013, a SEE-SP não deu continuidade ao esforço de organizar todas as suas ações sob a chancela de um único programa, marca da gestão Voorwald/Palma Filho e da execução do PECSP no quadriênio 2011-2014 (VOORWALD; PALMA FILHO, 2013; VOORWALD, 2014).

\section{Formalização da Parceria e Avanço da Heterarquização (2015-2018)}

A relação entre a SEE-SP e a APE antecede em quase uma década o convênio do PECSP. Na esteira do Decreto n. 48.781/2004, que instituiu o programa Escola da Família no estado de São Paulo, a Resolução SE (Resolução da Secretaria da Educação) n. 24/2005 regulamentou as parcerias entre as Associações de Pais e Mestres e as organizações da sociedade civil. Era uma atualização da Resolução SE n. 234/1995, de mesmo teor, que primeiro instituiu a Escola em Parceria no estado de São Paulo (SOUSA, 2000). Em ambas as normativas, a SEE-SP ressaltava a importância da participação da sociedade civil para a recuperação e a melhoria da qualidade do ensino público paulista, bem como a necessidade de descentralizar e desconcentrar ações para propiciar a autonomia de gestão em nível local.

Como é possível constatar no website da APE, a história da organização se confunde com a própria história da Escola em Parceria no estado de São Paulo. Diversos marcos da linha do tempo da APE se relacionam a programas da SEE-SP, com evidente destaque para o PECSP ${ }^{19}$. Jair Ribeiro da Silva Neto, sócio do Banco Indusval \& Partners e diretor-presidente da APE, também fez parte do CEE-SP entre 2013 e 2019, período que compreendeu toda a vigência do convênio com a SEE-SP ${ }^{20}$. Nos termos da Lei Estadual n. 10.403/1971 (art. $2^{\circ}$ ), cabe ao CEE-SP se manifestar sobre a assinatura de contratos entre a SEE-SP e o setor privado ${ }^{21}$.

A partir da formalização da parceria entre a APE e a SEE-SP, "objetivando a conjugação de esforços para execução do PECSP” (SÃO PAULO, 2018, f. 405), a implantação de subprogramas e projetos associados aos pilares do PECSP foi paulatinamente diluída na execução do convênio. Assim, no quadriênio 2015-2018, a parceria público-privada passou a se confundir com o próprio PECSP.

O contrato foi assinado em 29 de outubro de 2014 e a justificativa para a celebração do convênio era a necessidade de apoio especializado para o PECSP - notadamente para um de seus subprogramas - o Programa 
Ensino Integral (PEI) -, tendo em vista a necessidade de entregar resultados e cumprir metas que, até então, vinham sendo acompanhadas pelo Escritório de Projetos vinculado à Assessoria Técnica e de Planejamento (ASTEP) da SEE-SP. O primeiro documento juntado ao processo administrativo (autuado em 04 de junho de 2014) foi um memorando de 25 de março de 2014 em que Valéria de Souza, assessora técnica do gabinete da SEE-SP, apresentava ao secretário Voorwald uma "proposta de convênio elaborado em conjunto com as equipes técnicas dos demais Pilares que integram o PECSP” (SÃO PAULO, 2018, f. 7). A assessora, que coordenava desde 2010 a equipe responsável pelo fortalecimento da política de ensino integral da SEE-SP (depois incorporada ao pilar 3 do PECSP), ressaltava

[...] que a experiência positiva de contar com apoio especializado em momentos específicos da execução das ações do Programa Ensino Integral, sempre sob as diretrizes, coordenação e gestão da Secretaria, importante apoio na construção e aperfeiçoamento do Programa, permite sugerir que esse aporte seja ampliado para outros Pilares e suas respectivas ações do Programa Educação - Compromisso de São Paulo (SÃO PAULO, 2018, f. 6, grifos nossos).

Souza se referia à participação do Instituto de Corresponsabilidade pela Educação (ICE) na implantação do PEI a partir de 2012. A aproximação entre a SEE-SP e o ICE foi intermediada pela APE, que ali já ensaiava o papel de boundary spanner que passaria a desempenhar mais propriamente a partir de 2015. Segundo Valéria de Souza, as demais áreas (os responsáveis pelo acompanhamento das políticas referentes aos outros quatro pilares do PECSP) também viam a necessidade de poder contar com esse tipo de apoio.

Três dias depois, em 28 de março de 2014, o gabinete do secretário Voorwald enviou ao diretorpresidente da APE, Jair Ribeiro, o Ofício GS n. 100/2014 com a proposta de convênio preparada por sua assessoria (SÃO PAULO, 2018, f. 8-14). Curiosamente, a resposta ao ofício veio logo no dia seguinte, acompanhada de uma vasta documentação para a formalização da parceria ${ }^{22}$ e de um plano de trabalho detalhado. Respondendo à demanda da SEE-SP, a entidade se apresentou como esperado: uma Organização da Sociedade Civil de Interesse Público (OSCIP) com vários anos de experiência em parcerias com escolas públicas; declarou-se bem-sucedida no atingimento de metas e resultados em políticas educacionais; e propôs "modelagens" para todas as macroestratégias do PECSP, fazendo referência aos seus cinco pilares (embora com ênfase nos três primeiros).

A rapidez com que a APE aquiesceu ao convite da SEE-SP não surpreende, uma vez que a parceria informal já existia e que Jair Ribeiro integrava o CEE-SP desde julho de 2013. A sala onde o CEE-SP se reúne semanalmente fica no mesmo andar, a alguns metros de distância, do gabinete do secretário da educação, ilustrando que a proximidade entre os atores interessados no convênio era, inclusive, física. Conquanto o processo administrativo informe que Voorwald consultou a APE sobre o interesse da entidade na celebração do convênio após ser provocado por um memorando de sua assessoria de gabinete, esse foi um mero acerto procedimental. A operação fora previamente arranjada por todos os interessados.

Formalizado o convênio, o PECSP tornou-se indistinguível da própria parceria público-privada. Os planos de trabalho e relatórios de atividades juntados ao processo administrativo seguiram organizados em torno dos cinco pilares originais do PECSP, mas apenas aquilo que era estritamente objeto do convênio aparecia elencado sob cada pilar: ações, metas intermediárias e metas finais contratualizadas.

A grande rede de atores políticos vinculados ao PECSP a partir de 2015, com suas intrincadas relações, é ilustrada no grafo da Fig. 1, que identifica as instituições (públicas em vermelho e privadas em $a z u l$ ), os programas/projetos (em cor-de-rosa) e as pessoas físicas (em cinza) mais conectados ao núcleo da rede. O grafo demonstra, em primeiro lugar, a centralidade da APE na rede política. Altamente conectada, 
a organização aparece junto à SEE-SP, a seus órgãos internos e às instâncias de acompanhamento do PECSP. Sua localização no grafo indica que o trabalho da APE transcendia o papel de mero prestador de serviços da SEE-SP. A organização tornou-se parte da própria estrutura de governança do PECSP, o que é uma evidência das reconfigurações que caracterizam a heterarquização do Estado.

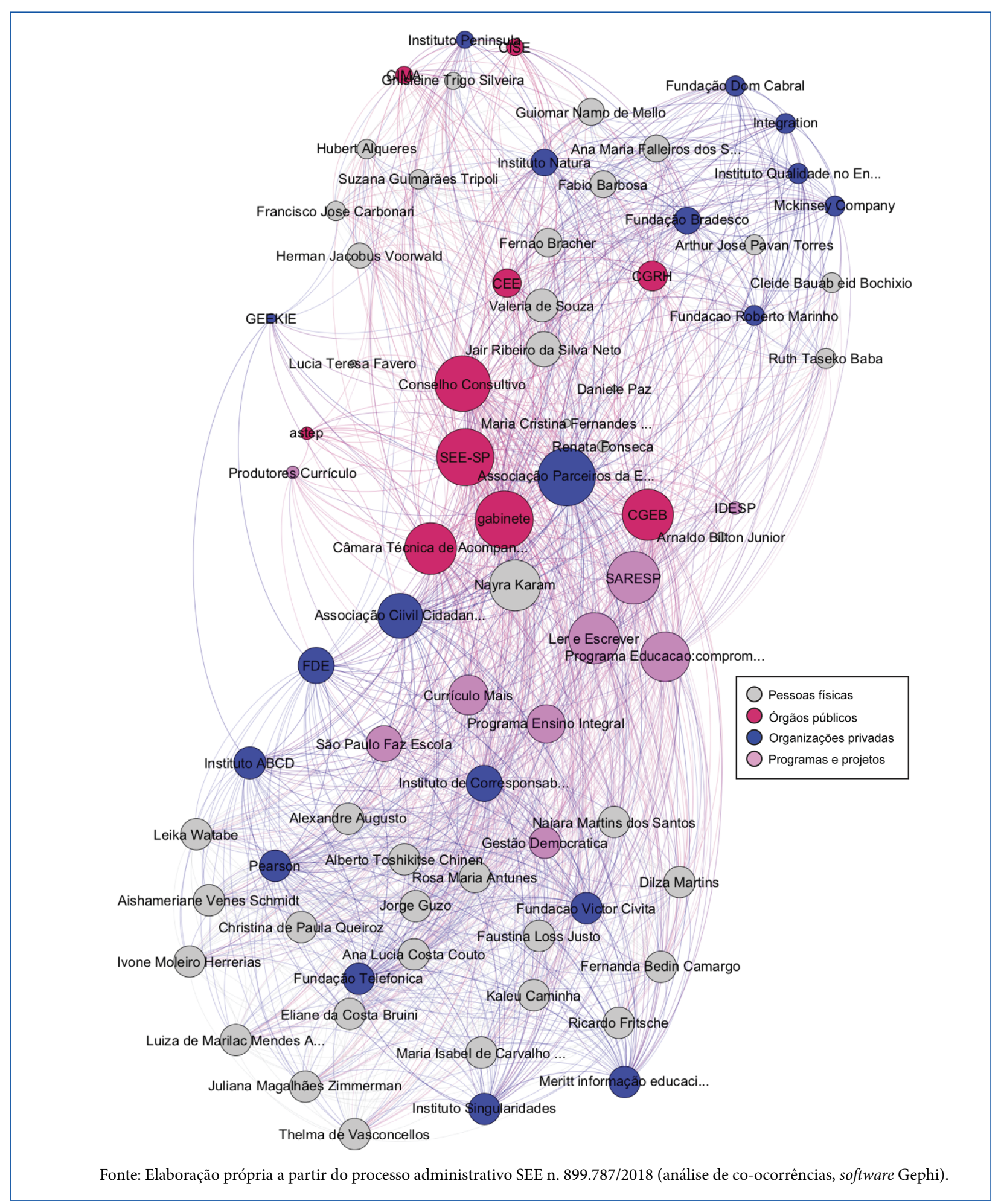

Figura 1. Grafo da rede do PECSP, incluindo conexões entre organizações, pessoas físicas (setores público e privado) e programas/projetos relacionados ao PECSP. 
Em segundo lugar, programas e projetos da SEE-SP sem relação aparente com o PECSP, como o Saresp (Sistema de Avaliação de Rendimento Escolar do Estado de São Paulo), também aparecem no grafo, dando a ver a porosidade entre as políticas educacionais no estado e indicando que a APE, inicialmente contratada para dar "apoio especializado" à execução do PECSP, passou a interagir e a influenciar diversas outras políticas vigentes na rede de ensino paulista.

As pessoas físicas também desempenham papéis relevantes no estabelecimento e na multiplicação das relações público-privadas, a exemplo do secretário Voorwald e da assessora Valéria de Souza, ligados à SEE-SP, bem como de pessoas ligadas à APE, como Jair Ribeiro (diretor-presidente) e Lúcia Fávero (diretoraexecutiva). Todos estão pessoal ou institucionalmente relacionados a diversos atores e organizações. Contudo, uma análise mais refinada do papel das pessoas físicas em torno da rede de governança do PECSP ultrapassa o escopo do presente artigo.

\section{Expandindo as Fronteiras da Privatização}

A partir da assinatura do contrato com a SEE-SP, a APE passou a operar na SEE-SP como intermediária de parceiros privados subsidiariamente contratados para ações específicas relacionadas aos pilares do PECSP. O programa, que antes assumia o papel de "política de Estado", passou a funcionar como uma plataforma para a realização de políticas educacionais experimentais, projetos-piloto e ações em microescala na rede estadual.

Conquanto diluído na parceria público-privada homônima, os fundamentos do PECSP ainda podem ser identificados nas políticas executadas pela SEE-SP no quadriênio 2015-2018. Algumas delas, que já davam corpo ao PECSP no quadriênio anterior, foram preservadas e ampliadas, como o PEI. Outras foram sofisticadas, como as políticas de gestão para resultados, redesenhadas em 2016 pela Falconi Educação, empresa de consultoria subcontratada pela APE. Outras, ainda, foram respostas do governo paulista ao terremoto político das ocupações escolares que sacodiu a SEE-SP no final de 2015, como o projeto Gestão Democrática (ARELARO et al., 2016).

No âmbito das atividades referentes ao pilar 1, por exemplo, a Fundação Dom Cabral (FDC), subcontratada da APE, desenvolveu, entre 2015 e 2016, o diagnóstico e a modelagem de um programa de formação de líderes e gestores educacionais para a SEE-SP, que culminou no projeto Academia de Líderes da SEE-SP (SÃO PAULO, 2018, f. 435-657; 1229-1238). Este é um exemplo dos vários projetos-piloto que, uma vez iniciados e apresentados nos relatórios de atividades da APE (SÃO PAULO, 2018), foram rapidamente descontinuados. Após maio de 2016, não encontramos quaisquer referências - nem no processo administrativo, nem em materiais de divulgação da SEE-SP, nem nos relatórios anuais da FDC - à Academia de Líderes da SEE-SP ${ }^{23}$.

Já o pilar 2, teve algumas ações descontinuadas e outras iniciadas no período, com o aprofundamento das instâncias de controle e monitoramento de indicadores escolares a partir do programa Gestão em Foco e do Método de Melhoria de Resultados (MMR). O programa tem objetivos muito semelhantes, senão idênticos, aos de uma ação já realizada no âmbito do PECSP e gestada dentro do próprio governo de São Paulo: o Plano de Ação Participativo (PAP), implantado em 2012 por iniciativa conjunta da SEE-SP e da então Secretaria de Gestão Pública (PAULA, 2017).

Entre as várias ações em microescala realizadas no âmbito do convênio está o programa Compasso Socioemocional, parceria (intermediada pela APE) entre a SEE-SP e o Instituto Vila Educação para a formação de professores em 21 escolas do PEI em 2017 (SÃO PAULO, 2018, f. 1964-2023). O programa foi uma ação 
"voluntária" do instituto parceiro em associação com um parceiro terciário, o Instituto Phi. As estratégias apresentadas para a formaçãodos docentes das escolas participantes incluíam, por exemplo, "Exercícios para o Cérebro, para desenvolver nos alunos as funções executivas como atenção, memória operacional e controle inibitório" (SÃO PAULO, 2018, f. 1972).

A rede apresentada na Fig. 1 é muito mais aninhada (estrutura centralizada, em diversas camadas) do que modular (com diversos subgrupos pouco conectados entre si). Assim, é no núcleo da rede que serão encontrados os nós com maior número de conexões (os hubs da rede política). A fim de produzir uma visualização mais clara do núcleo da rede, construímos uma subrede selecionando apenas os nós com maior centralidade (hub score > 0,3). Assim, obtivemos o grafo da Fig. 2.

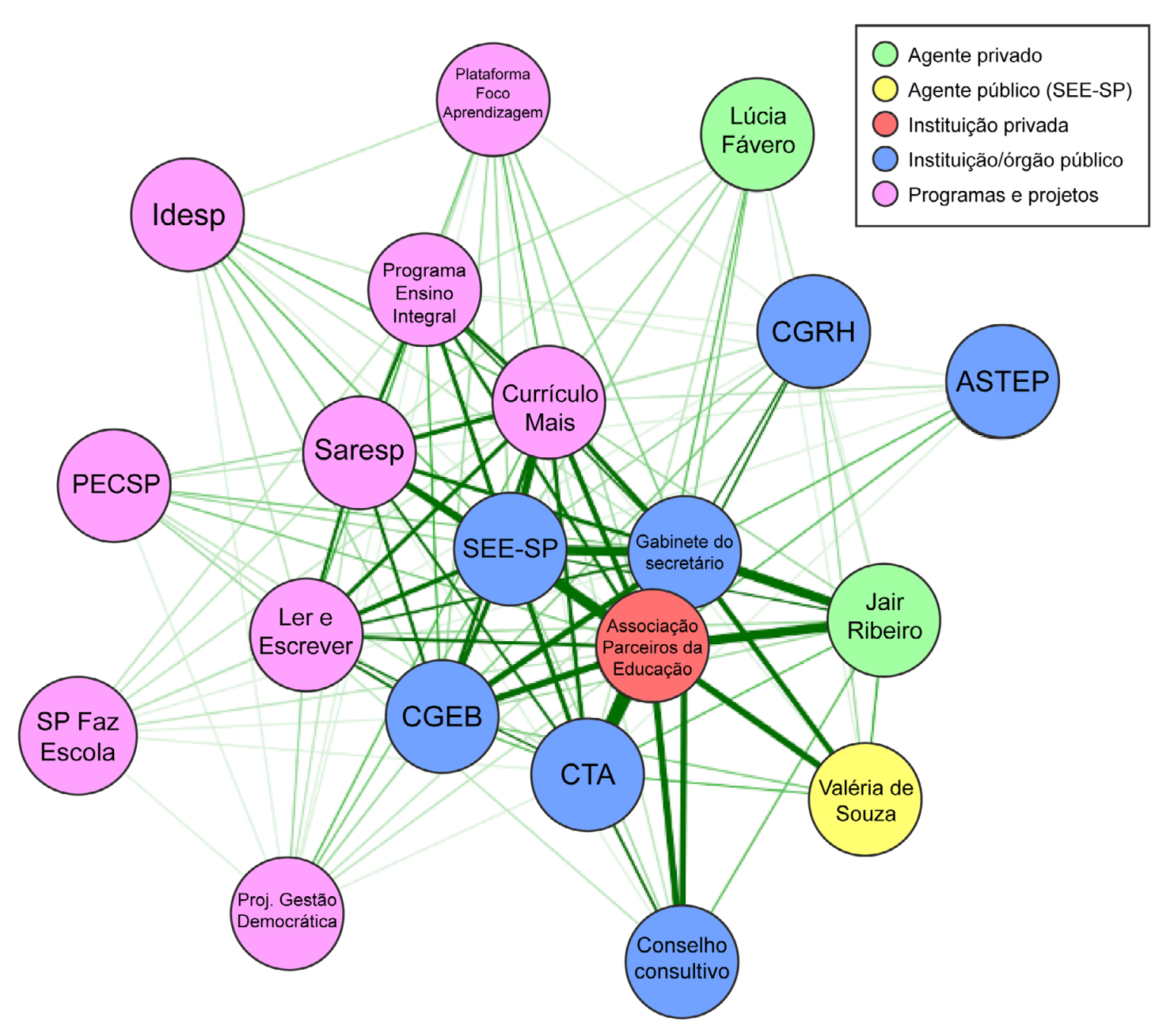

ASTEP: Assessoria Técnica de Planejamento; CGEB: Coordenadoria de Gestão da Educação Básica; CGRH: Coordenadoria de Gestão de Recursos Humanos; CTA: Câmara Técnica de Acompanhamento do PECSP; Idesp: Índice de Desenvolvimento da Educação do Estado de São Paulo; PECSP: Programa Educação - Compromisso de São Paulo; Saresp: Sistema de Avaliação de Rendimento Escolar do Estado de São Paulo; SEE-SP: Secretaria da Educação do Estado de São Paulo

Fonte: Elaboração própria a partir do processo administrativo SEE n. 899.787/2018 (análise de co-ocorrências, algoritmo próprio).

Figura 2. Núcleo da rede do PECSP, mostrando apenas os nós mais centrais (hub score $>0,3$ ). A espessura das linhas é proporcional à contagem de co-ocorrências. 
Analisando em detalhe o núcleo da rede principal, constatamos que o relacionamento da APE com programas e projetos não abarcados pelo convênio - como Saresp, São Paulo Faz Escola (política de centralização curricular) e programa Ler e Escrever - não é um fenômeno secundário na estrutura de governança do PECSP. Ao contrário, a parceria público-privada afeta e é afetada por políticas públicas já existentes na rede de ensino, modificando sentidos e estruturas de governança pública que extrapolam o escopo inicial e oficial da parceria.

Além de estimular a porosidade entre as políticas educacionais da SEE-SP, a parceria públicoprivada com a APE viabilizou a participação de um grande número de organizações privadas na gestão da educação paulista, diluindo o papel do Estado na gestão direta das políticas e fomentando a governança em rede. No grafo da Fig. 3, é possível ver como não apenas a APE está diretamente conectada a várias instituições/órgãos públicos (em $a z u l$ ) a partir do núcleo da rede, mas que uma série de organizações privadas (em vermelho) também passam a compor a rede a partir de suas conexões com a APE.

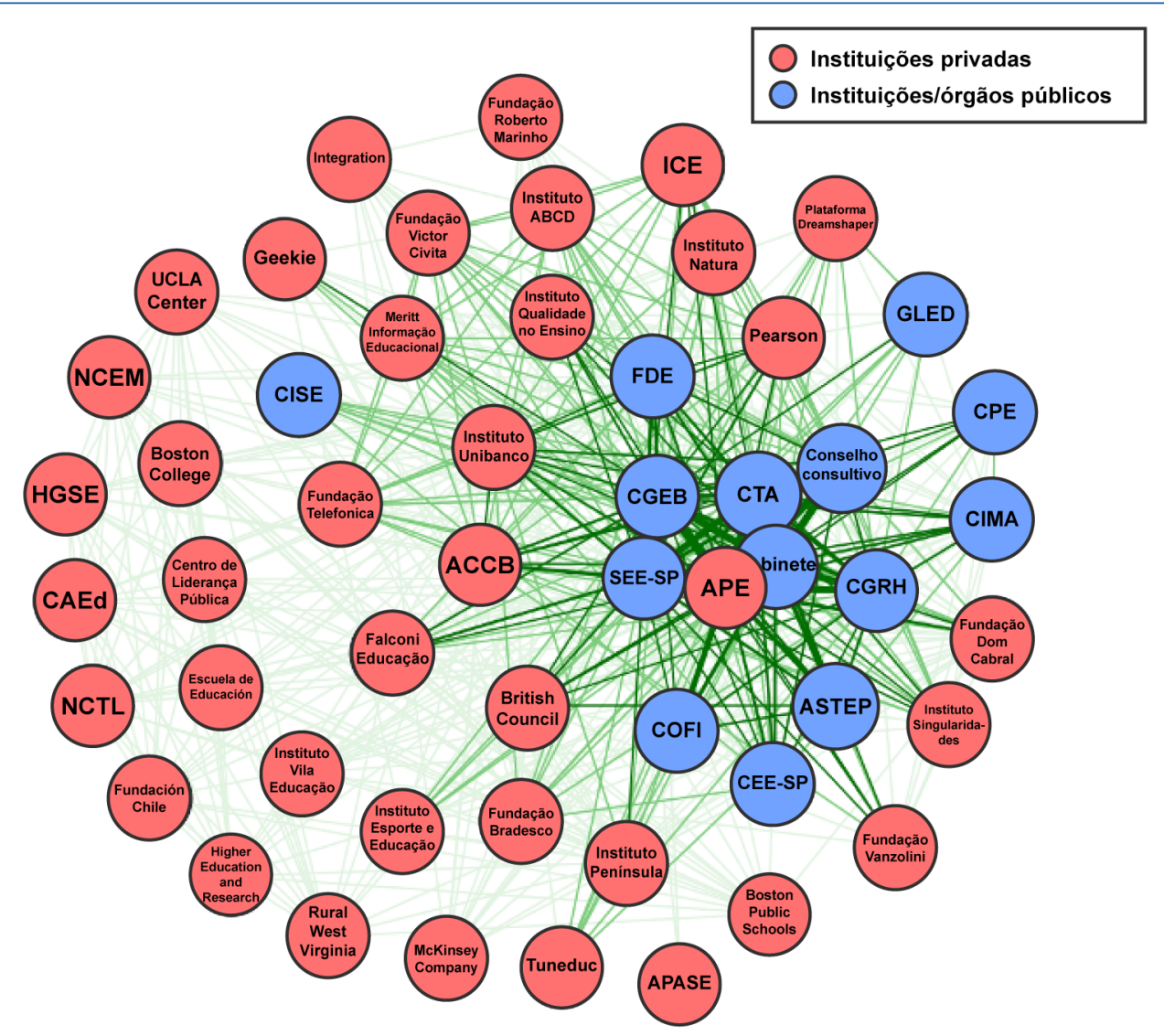

ACCB: Associação Civil Cidadania Brasil; APASE: Sindicato dos Supervisores de Ensino do Magistério Oficial no Estado de São Paulo; APE: Associação Parceiros da Educação; ASTEP: Assessoria Técnica de Planejamento; CAEd: Centro de Políticas Públicas e Avaliação da Educação (UFJF); CEE-SP: Conselho Estadual de Educação de São Paulo; CGEB: Coordenadoria de Gestão da Educação Básica; CGRH: Coordenadoria de Gestão de Recursos Humanos; CIMA: Coordenadoria de Informação, Monitoramento e Avaliação; CISE: Coordenadoria de Infraestrutura e Serviços Escolares; COFI: Coordenadoria de Orçamento e Finanças; CPE: Comitê de Políticas Educacionais (SEE-SP); CTA: Câmara Técnica de Acompanhamento do PECSP; FDE: Fundação para Desenvolvimento da Educação; GLED: Grupo de Legislação Educacional (SEE-SP); HGSE: Harvard Graduate School of Education; ICE: Instituto de Corresponsabilidade pela Educação; NCEM: National College for Education Management; NCTL: National College for Teaching and Leadership; SEE-SP: Secretaria da Educação do Estado de São Paulo

Fonte: Elaboração própria a partir do processo administrativo SEE n. 899.787/2018 (análise de co-ocorrências, algoritmo próprio).

Figura 3. Rede de instituições/órgãos públicos e organizações privadas constelados no PECSP. A espessura das linhas é proporcional à contagem de co-ocorrências. 
No centro da rede, a APE desempenha o papel de boundary spanner, transpondo barreiras e conectando organizações que não estariam conectadas de outra maneira (BALL, 2016). Mais do que isso, a organização tem a prerrogativa contratual de controlar a entrada de novos atores privados na rede, decidindo quais deles poderão estabelecer vínculos diretos ou indiretos com o governo paulista. A APE, portanto, atua no mesmo nível da SEE-SP; o que novamente evidencia o processo de heterarquização do Estado. O boundary spanning operado pela APE pode ser mais claramente visualizado no grafo da Fig. 3, que mostra apenas as instituições/órgãos públicos e organizações privadas constelados na rede do PECSP.

O grafo sugere que, no quadriênio 2015-2018, a privatização da educação em São Paulo envolveu múltiplos atores em uma rede aninhada em torno de um núcleo central, tendo a APE como hub principal da rede (em vermelho). Imediatamente ao redor (em $a z u l$ ), figuram a SEE-SP e seus diversos setores internos, além de órgãos públicos como o CEE-SP e a Fundação para o Desenvolvimento da Educação (FDE).

Já nas camadas mais externas da rede (também em vermelho), aparecem diversas outras organizações privadas. Mais próximas ao núcleo e com conexões mais fortes, estão as organizações subcontratadas pela APE (boundary spanner) para executar ações no âmbito do convênio do PECSP: empresas de tecnologia, de consultoria educacional e institutos e fundações empresariais prestadores de serviços. Mais distantes do núcleo e com conexões mais fracas, estão as organizações cujo trabalho é referenciado nos projetos abarcados pelo convênio: instituições de pesquisa ligadas a universidades (sobretudo estrangeiras), think tanks e empresas internacionais de consultoria. Com efeito, a força das conexões entre os nós (a espessura das linhas) sugere relações de diferentes naturezas - o que, no caso da Fig. 3, somente pode ser inferido a partir de uma nova leitura da fonte documental e de uma pesquisa adicional sobre essas organizações.

Assim como nos grafos das Figs. 1 e 2, os nós que representam a APE e o gabinete da SEE-SP aparecem praticamente sobrepostos na Fig. 3. Isso só vem reforçar que, nos processos de privatização da educação, as estruturas estatais parecem estar cada vez mais deslocalizadas sobre redes políticas complexas, que suplantam governos e que embaçam a própria distinção entre "público" e "privado".

\section{Conclusões}

A análise das redes políticas em torno do PECSP entre 2015 e 2018 aponta para a complexificação das relações público-privadas na gestão da educação e na execução de políticas educacionais no estado de São Paulo. Tomando esse caso como exemplo de heterarquização da governança da educação, identificamos três dinâmicas de complexificação: 1) a incorporação formal de uma organização privada como parte da estrutura de governança da educação pública; 2 ) a porosidade entre políticas educacionais e a possibilidade de mobilidade de uma organização privada para além daquilo que foi inicialmente contratualizado; e 3) a atuação de uma organização privada na ampliação da rede de governança, facilitando a entrada de outras organizações (que passam a participar das dinâmicas anteriores).

Primeiramente, constatamos que, em contraste com o que ocorreu no quadriênio 2011-2014, a parceria público-privada entre a APE e a SEE-SP - cuja finalidade era apoiar a execução do PECSP -, tornou-se indistinguível do próprio programa a partir de 2015. A APE passou a formular, executar, gerir e avaliar atividades de responsabilidade da SEE-SP como se fizesse parte da própria estrutura burocrática do Estado. Tal dinâmica ilustra o processo de heterarquização (JESSOP, 2016), com a transferência de responsabilidades e de atividades anteriormente exclusivas do Estado (PERONI, 2013). Dessa análise emerge o papel das pessoas físicas na privatização da educação, processo que também se desenvolve no nível e a partir das relações pessoais no interior da estrutura burocrática heterarquizada. Esse aspecto será explorado em trabalhos futuros. 
Em segundo lugar, embora o convênio estivesse originalmente circunscrito ao PECSP, a APE passou a interagir e a influenciar diversas outras políticas da SEE-SP, o que mostra que uma única parceria público-privada pode promover a complexificação da governança e aumentar a indefinição e a opacidade de processos e papéis desempenhados pelos setores público e privado.

Por fim, a parceria público-privada entre a APE e a SEE-SP possibilitou a entrada de diversas outras organizações privadas na governança da educação paulista. Atuando como boundary spanner, a APE passou a facilitar e a mediar parcerias secundárias e terciárias, complexificando ainda mais as redes e as relações envolvidas no processo amplo - mas nem por isso pouco concreto - de privatização da educação.

\section{Contribuições dos Autores}

Problematização e Conceitualização: Cássio, F; Avelar, M; Coleta de dados: Cássio, F; Novaes, TAF; Metodologia: Cássio, F; Avelar, M; Travitzki, R; Novaes, TAF; Análise: Cássio, F; Avelar, M; Travitzki, R; Redação - Primeira versão: Cássio, F; Avelar, M; Revisões e aprovação da versão final: Cássio, F.

\section{Notas}

1. Disponível em: www.saopaulo.sp.gov.br/ultimas-noticias/estado-e-sociedade-firmam-compromisso-de-sao-paulopela-educacao-1. Acesso em: 06 set. 2020.

2. Voorwald pediu demissão em 04 de dezembro de 2015, desgastado politicamente em razão da polêmica "reorganização escolar" e das massivas ocupações escolares que dela sobrevieram.

3. O Decreto Estadual n. 59.215/2013, por exemplo, disciplina a instrução de processos administrativos de convênios no âmbito do governo paulista. Ver também: www.parcerias.sp.gov.br/Parcerias/Legislacao. Acesso em: 20 jul. 2020.

4. Em 2018, a SEE-SP modificou seus procedimentos de protocolo e sua sistemática de numeração de processos, de modo que o processo administrativo SEE n. 2.737/2014 passou a ser identificado como SEE n. 899.787/2018. Isso explica por que um processo autuado em 2014 seja referenciado neste artigo como "SÃO PAULO, 2018".

5. O algoritmo foi construído na linguagem $\mathrm{R}$, utilizando-se, adicionalmente, os pacotes igraph para a manipulação dos grafos (CSÁRDI; NEPUSZ, 2006); rnetcarto para o cálculo da modularidade por anelamento simulado (DOULCIER; STOUFFER, 2015); e UNODF para o cálculo do aninhamento das redes (CANTOR et al., 2017).

6. Na matriz de adjacência, $o$ valor, que antes era 0 , torna-se 1 .

7. Na matriz de adjacência, o valor, que antes era 1, torna-se 2 .

8. Isso quer dizer que elementos de categorias diferentes (agentes públicos, organizações privadas etc.) aparecem nos grafos como nós equivalentes. Para a terminologia básica da teoria de grafos, ver Diestel (2017).

9. As relações entre os nós foram inferidas apenas pela co-ocorrência entre termos nos documentos analisados e, portanto, são representadas por arestas equivalentes, sem qualquer direção preferencial entre dois nós conectados (DIESTEL, 2017).

10. Disponível em: www.educacao.sp.gov.br/noticias/governador-anuncia-programa-de-acoes-e-convida-a-sociedadepara-compromisso-pela-educacao. Acesso em: 20 jul. 2020.

11. Ver nota 1. Sobre a referida ênfase na participação da rede de ensino na construção do Programa Educação 
- Compromisso de São Paulo (PECSP), ver Voorwald e Palma Filho (2013). Para duas análises sobre o PECSP, ver ainda Dantas (2013) e Mesko (2018).

12. Disponível em: https://catracalivre.com.br/educacao/a-transformacao-da-qualidade-da-educacao-basica-publicano-brasil. Acesso em: 20 jul. 2020.

13. O manifesto apresenta propostas para a transformação da educação nacional a partir das respostas de doze especialistas em educação à seguinte pergunta: "Caso fosse eleito Presidente da República ou Governador do Estado, quais as cinco grandes ações/iniciativas transformacionais que tomaria para efetivamente resolver o problema da qualidade do ensino público básico, a fim de que o país possa atingir os níveis educacionais dos países desenvolvidos até o ano de 2022?" O grupo era formado por Carlos Roberto Jamil Cury, Cláudio de Moura Castro, Eduardo Giannetti da Fonseca, Eunice Durham, Guiomar Namo de Mello, José Francisco Soares, Luís Carlos de Menezes, Maria Helena Guimarães de Castro, Mauro Aguiar, Mozart Neves Ramos, Reynaldo Fernandes e Ruben Klein. Embora não seja o objetivo deste artigo analisar os vínculos pregressos entre esses atores e a SEE-SP, é interessante notar que, entre eles, há uma ex-secretária da educação do estado de São Paulo, Maria Helena Guimarães de Castro (janeiro de 2007 - março de 2009), e diversas pessoas que integram ou já integraram o CEE-SP.

14. Este trecho e o link para o manifesto de 2010 ainda podem ser encontrados no website da APE Rio de Janeiro. Disponível em: www.parceirosdaeducacaorj.org.br/politica-publica. Acesso em: 20 jul. 2020.

15. Ver nota 1.

16. A partir de $1^{\circ}$ de janeiro de 2015, a Secretaria de Gestão Pública passou a ser denominada Secretaria de Governo (Decreto Estadual n. 61.035/2015).

17. Disponível em: http://estaticog1.globo.com/2016/12/13/Plano_de_governo_Alckmin.pdf. Acesso em:20 jul. 2020.

18. Ver nota 10.

19. Disponível em: https://parceirosdaeducacao.org.br/quem-somos/\#historia. Acesso em: 20 jul. 2020.

20. Disponível em: https://deolhonosconselhos.wordpress.com/composicao-do-cee-sp; e www.ceesp.sp.gov.br/ informacoes_uteis.php. Acesso em: 20 jul. 2020. Para uma análise das trajetórias dos membros do CEE-SP entre 1995 e 2018, ver Ferreira (2019).

21. Em seu Parecer n. 356/2014, o CEE-SP aprovou a celebração do convênio com a APE, mas recomendou, por motivos de transparência, que a SEE-SP publicizasse a lista de membros do Conselho Consultivo do PECSP, formado naquele momento por Geraldo Alckmin, Herman Voorwald, Cleide Bauab Eid Bochixio (secretária-ajunta e CGRH), Fernando Padula (chefe de gabinete), Guiomar Namo de Mello (CEE-SP), Ione Ribeiro Assunção (CIMA), Dione di Pietro (CISE), Silvia Galetta (EFAP), Maria Elizabete da Costa (CGEB), Valéria de Souza (assessora de gabinete), Ana Maria Diniz (Instituto Península), Bernardo Gradin (Instituto Inspirare), Denise Aguiar (Fundação Bradesco), Fernão Bracher (Instituto Acaia), Jair Ribeiro (APE), Antonio Mathias (Fundação Itaú Social), Carlos Jereissati (Grupo Iguatemi), Fábio Barbosa (Editora Abril), Guilherme Leal (Instituto Natura) e Ricardo Henriques (Instituto Unibanco). Em 29 de outubro de 2014, por votação unânime, o CEE-SP manifestou-se favoravelmente à celebração do convênio. O conselheiro Jair Ribeiro da Silva Neto se absteve de votar (SÃO PAULO, 2018, fls. 310A-314A).

22. Estatuto social da organização, documentos pessoais dos representantes legais da organização, ata de nomeação do responsável pela entidade e certidões negativas diversas.

23. Disponível em: www.fdc.org.br/sobreafdc/responsabilidade-social/relatorios-anual. Acesso em: 20 jul. 2020. O projeto é mencionado por Voorwald (2017), e alguns de seus conteúdos foram incluídos nas referências bibliográficas das Diretrizes de Formação Continuada para Gestores da SEE-SP (SÃO PAULO, 2017). 


\section{Referências}

ADRIÃO, T. Dimensões e formas da privatização da educação no Brasil: caracterização a partir de mapeamento de produções nacionais e internacionais. Currículo sem Fronteiras, v. 18, n. 1, p. 8-28, 2018.

ADRIÃO, T. et al. As parcerias entre prefeituras paulistas e o setor privado na política educacional: expressão de simbiose? Educação \& Sociedade, Campinas, v. 33, n. 119, p. 533-549, 2012. https://oi.org/10.1590/ S0101-73302012000200011

ADRIÃO, T.; PERONI, V. (orgs.). O público e o privado na educação: interfaces entre Estado e sociedade. São Paulo: Xamã, 2005.

ARELARO, L. R. G.; JACOMINI, M.; CARNEIRO, S. R. G. Limitações da participação e gestão "democrática” na rede estadual paulista. Educação \& Sociedade, Campinas, v. 37, n. 137, p. 1143-1158, 2016. https://doi. org/10.1590/ES0101-73302016167343

AVELAR, M.; BALL, S. J. Mapping new philanthropy and the heterarchical state: the Mobilization for the National Learning Standards in Brazil. International Journal of Educational Development, Amsterdam, v. 64, p. 65-73, 2019. https://doi.org/10.1016/j.ijedudev.2017.09.007

BALL, S. J. Global Education Inc: new policy networks and the neo-liberal imaginary. New York: Routledge, 2012.

BALL, S. J. Following policy: networks, network ethnography and education policy mobilities. Journal of Education Policy, v. 31 n. 5, p. 549-566, 2016. https://doi.org/10.1080/02680939.2015.1122232

BALL, S. J.; JUNEMANN, C. Networks, new governance and education. Bristol: Policy Press, 2012.

BRENNER, N.; PECK, J.; THEODORE, N. After neoliberalization? Globalizations, Colchester, v. 7, n. 3, p. 327-345, 2010. https://doi.org/10.1080/14747731003669669

CANTOR, M. et al. Nestedness across biological scales. PLoS ONE, v. 12, n. 2, e0171691, 2017. https://doi. org/10.1371/journal.pone.0171691

CSÁRDI, G.; NEPUSZ, T. The igraph software package for complex network research. InterJournal, Complex Systems, Cambridge, MA, v. 1695, n. 5, p. 1-9, 2006.

DANTAS, G. K. G. Política educacional paulista (1995-2012): dos primórdios da reforma empresarial à consolidação do modelo gerencial. 2013. 153 f. Tese (Doutorado em Educação) - Faculdade de Filosofia e Ciências, Universidade Estadual Paulista "Júlio de Mesquita Filho", Marília, 2013.

DANTÔNIO, D. V. B. O fortalecimento da governança e do planejamento na Secretaria da Educação do Estado de São Paulo. 2014. Trabalho apresentado ao VII Congresso CONSAD de Gestão Pública, Brasília, 25-27 mar. 2014. Disponível em: https://cutt.ly/1dzEvmL. Acesso em: 20 jul. 2020.

DARDOT, P.; LAVAL, C. A nova razão do mundo: ensaio sobre a sociedade neoliberal. São Paulo: Boitempo, 2016. (Coleção Estado de Sítio.)

DI PIERRO, M. C.; XIMENES, S. B. Políticas e direitos educativos dos jovens e adultos no estado de São Paulo: notas de pesquisa e relato de intervenção. 2011. Trabalho apresentado ao $25^{\circ}$ Simpósio Brasileiro de Política e Administração da Educação, São Paulo, 26-30 abr. 2011. Disponível em: https://cutt.ly/HfCVKWz. Acesso em: 20 jul. 2020. 
DIESTEL, R. Graph Theory. 5·ed. Berlin/Heidelberg: Springer-Verlag, 2017. (Graduate Texts in Mathematics.) DOULCIER, G.; STOUFFER, D. Rnetcarto: Fast Network Modularity and Roles Computation by Simulated Annealing. R package version 0.2.4.2015.

FERREIRA, A. C. T. C. As elites político-administrativas à frente da educação paulista: trajetórias dos membros do Conselho Estadual de Educação de São Paulo de 1995 a 2018. 2019. 154 f. Dissertação (Mestrado em Sociologia) - Faculdade de Filosofia, Letras e Ciências Humanas, Universidade de São Paulo, São Paulo, 2019.

GOUlART, D. C.; CÁSSIO, F. L.; XIMENES, S. B. Rede Escola Pública e Universidade: produção do conhecimento para/com as lutas educacionais. Revista Brasileira de Educação, Rio de Janeiro, v. 24, e240048, 2019. https://doi.org/10.1590/s1413-24782019240048

JESSOP, B. The future of the capitalist state. Cambridge, UK: Polity Press, 2002.

JESSOP, B. State Theory. In: ANSELL, C.; TORFING, J. (eds.). Handbook on Theories of Governance. Cheltenham: Edward Elgar Publishing, 2016. p. 71-85.

LARNER, W. Neoliberalism? Environment and Planning D: Society and Space, London, v. 21, n. 5, p. 509512, 2003. https://doi.org/10.1068/d2105ed

LONG, J. C.; CUNNINGHAM, F. C.; BRAITHWAITE, J. Bridges, brokers and boundary spanners in collaborative networks: a systematic review. BMC Health Services Research, v. 13, n. 158, 2013. https://doi. org/10.1186/1472-6963-13-158

MESKO, A. S. R. O programa “Educação - Compromisso de São Paulo" e as estratégias de implementação das políticas empresariais na gestão escolar. 2018. 140 f. Dissertação (Mestrado em Educação) - Faculdade de Educação, Universidade Estadual de Campinas, Campinas, 2018.

PAULA, D. A. G. Prática de planejamento escolar na rede estadual paulista de ensino: Plano de Ação Participativo para escolas (PAP). 2017. 168 f. Dissertação (Mestrado em Educação) - Escola de Filosofia, Letras e Ciências Humanas, Universidade Federal de São Paulo, Guarulhos, 2017.

PERONI, V. M. V. (org.). Redefinições das fronteiras entre o público e o privado: implicações para a democratização da educação. Brasília: Liber Livro, 2013.

RHODES, R. A. W. The New Governance: governing without government. Political Studies, Oxford, v. 44, n. 4, p. 652-667, 1996. https://doi.org/10.1111/j.1467-9248.1996.tb01747.x

SÃO PAULO (Estado). Secretaria da Educação do Estado de São Paulo. Diretrizes de formação continuada para gestores da SEE-SP. São Paulo: Secretaria da Educação do Estado de São Paulo/Escola de Formação e Aperfeiçoamento de Professores, 2017. Disponível em: https://cutt.ly/YdzWKli. Acesso em: 20 jul. 2020.

SÃO PAULO (Estado). Secretaria da Educação do Estado de São Paulo. Processo Administrativo SEE n. 899.787/2018. Convênio Programa Educação - Compromisso de São Paulo, 2018. 9 v. Mimeo.

SHIROMA, E. O. Redes, experts e a internacionalização de políticas educacionais. Revista de Estudios Teóricos y Epistemológicos en Política Educativa, Buenos Aires, v. 5, e2014425, 2020. https://doi. org/10.5212/retepe.v.5.14425.003 
SHIROMA, E. O.; EVANGELISTA, O. Estado, capital e educação: reflexões sobre hegemonia e redes de governança. Educação \& Fronteiras, Dourados, v. 4, n. 11, p. 21-38, 2014.

SOUSA, S. M. Z. L. Parceria escola-empresa no estado de São Paulo: mapeamento e caracterização. Educação \& Sociedade, Campinas, v. 21, n. 70, p. 171-188, 2000. https://doi.org/10.1590/S0101-73302000000100010

TRIPODI, Z. F.; SOUSA, S. Z. Do governo à governança: permeabilidade do estado a lógicas privatizantes na educação. Cadernos de Pesquisa, São Paulo, v. 48, n. 167, p. 228-253, 2018. https://doi. org/10.1590/198053144800

VOORWALD, H. J. C. Novos desafios da rede estadual paulista. In: NEGRI, B.; TORRES, H. G.; CASTRO, M. H. G. (orgs.). A educação básica no estado de São Paulo: avanços e desafios. São Paulo: Fundação Seade/ FDE, 2014. p. 389-409.

VOORWALD, H. J. C. A educação básica pública tem solução? São Paulo: Editora Unesp, 2017.

VOORWALD, H. J. C.; PALMA FILHO, J. C. Políticas públicas e educação: diálogo \& compromisso. São Paulo: Secretaria da Educação, 2013.

WILLIAMS, P. The competent boundary spanner. Public Administration, Oxford, v. 80, n. 1, p. 103-124, 2002. https://doi.org/10.1111/1467-9299.00296

\section{Sobre os Autores}

Fernando Cássio é doutor em Ciências pela Universidade de São Paulo (USP). Professor do Centro de Ciências Naturais e Humanas da Universidade Federal do ABC (CCNH/UFABC). Membro do grupo de pesquisa "Direito à Educação, Políticas Educacionais e Escola" (DiEPEE) da UFABC. Integrante da Rede Escola Pública e Universidade (REPU). Suas pesquisas recentes focalizam as relações das políticas educacionais com as desigualdades educacionais e com processos de comoditização na educação pública.

Marina Avelar é pedagoga e mestre em Educação pela Universidade Estadual de Campinas (Unicamp). Doutora em Educação pelo UCL Institute of Education (Reino Unido). Pesquisa as interações das políticas educacionais com a privatização da educação, os novos atores privados, as redes sociais e a globalização.

Rodrigo Travitzki é bacharel e licenciado em Biologia pela Universidade Estadual de Campinas (Unicamp). Doutor em Educação pela Universidade de São Paulo (USP). Pesquisador de pós-doutorado no Laboratório de Avaliação Psicológica e Educacional da Universidade São Francisco (USF). Atua nas áreas de políticas educacionais e psicometria.

Thais Andrea Furigo Novaes é bacharel e licenciada em Química pela Universidade Federal do ABC (UFABC). Integra o grupo de pesquisa "Direito à Educação, Políticas Educacionais e Escola" (DiEPEE) da UFABC, no qual desenvolve pesquisa de mestrado relacionada às novas formas de privatização da educação no estado de São Paulo.

Recebido: 31 jul 2020

Aceito: 22 set 2020 